\title{
THE CONCEPT OF HUMAN FUNCTIONAL STATE IN RUSSIAN APPLIED PSYCHOLOGY
}

\author{
Anna B. Leonova \\ Lomonosov Moscow State University \\ Moscow
}

The concept of human functional states (HFS) is considered in the framework of activity regulation approach developed in Russian applied psychology. Aimed at the analysis of changes in regulatory mechanisms of on-going activity, structural methods for multilevel assessment of workers' states are discussed. Three different strategies of data integration are proposed regarding the types of essential practical problems. Their usability is exemplified with the help of two empirical studies concerned with reliability of fire-fighters' work in the Chernobyl Zone and effects of interruptions in computerized office environment. A general framework for applied HFS research is proposed in order to develop new ecologically valid psychodiagnostic procedures that can help to create efficient stress-management programs for enhancing human reliability and performance in complex job environment.

Keywords: activity regulation, job analysis, microstructure of cognitive processes, human functional state, workability, fatigue, mental effort, stress, interruption effects, computerized work

During decades the studies of operators' or, in a broader sense, human functional states (HFS) were one of the central topics of research in Russian applied psychology. They started to develop in the beginning of 1960s, the time of the foundation of engineering psychology and ergonomics in the former Soviet Union. From the beginning the needs of such "privileged" areas as space research, aviation, highly automated control systems largely shaped the content of HFS research. After a short delay the studies of HFS expanded to the other fields of industries and public services: energy production, transport, microelectronics, machinery construction, sport, medicine, education, etc. (for review see (Leonova, 1994)). The attempts to elaborate a comprehensive conceptual framework for HFS analysis were done in parallel with the accumu-

Preparation of the paper was supported by grant of The paper Russian Foundation of Fundamental Research (RFFI Project № 08-06-00284a). 
lation of empirical knowledge. As a result, a rather narrow physiological interpretation of the notion "functional state" (like "functional state of CNS" or "activation and level of arousal", etc. (Hockey, and Hamilton, 1983; Simonson, and Weiser, 1976)) was overcome. Efficiency with which human resources, both mental and organismic, are applied during the process of task execution became the essential point of HFS research (Leonova, 1994; Maryin, et al., 1992; Zinchenko, Leonova, and Strelkov, 1985). A development of this approach relates to the analysis of mechanisms of activity regulation under different job conditions (Leonova, 1998; Zinchenko, Leonova, and Strelkov, 1985). This helps to understand how the modes of individual coping change under the influence of situational demands, and whether they are really efficient or not. Furthermore, a functional status of a worker can be defined in terms of specific HFS syndromes that provide a better prognosis of his/ her performance and resistance to job constrains.

In contemporary research the concept of HFS is broadly used for the analysis of various human states relevant to work conditions - fatigue, monotony, different job stress reactions, physical and emotional strain, states of optimal workability, and so on. They are considered as different types of HFS syndromes. The spectrum of HFS syndromes is practically boundless since at any time a working person is in a certain state of mood, and the dynamics of state depends on the specifics of job situation. Therefore, the most important practical problems - the development of powerful tools for diagnostics and prevention of negative states - cannot be solved only by considering each specific case. A more general methodology has to be created that allows to differentiate between functional states based on their integrative characteristics.

This orientation closely corresponds to conventional issues on human factors at work, workload and work effort, stress at work and occupational health (Gopher, and Kimchi, 1989; Hockey, 1993; Leonova, et al., 2001a). It reflects the general intention to integrate information about the ways of individual adaptation to situational demands in coordination with resulting job outcomes (Cox, and Ferguson, 1994; Karasek, and Theorell, 1990). In the present paper we will try to outline the logic of analysis of the functional status of a worker that is proposed within the HFS concept. On this basis an attempt to create a more powerful and comprehensive methodology of stress management research will be made.

\section{The HFS concept and activity regulation approach}

Other than conventional interpretations of human or "mental" states (e.g., in terms of levels of psychophysiological activations, emotional or motivational states, conscious or unconscious states, etc.) the HFS concept concentrates on revealing the relations between work efficiency and individual resources that are utilized by a worker in order to perform a job. Two main points are emphasized in this definition.

Firstly, work efficiency indicators play the central role in the HFS analysis. They have to be taken into consideration in any criteria-based evaluation of HFS but are not limited only to listing parameters of direct work results, e.g. productivity and speed of performance. Two groups of criteria: reliability of human functioning and internal costs of activity - are used to describe efficient work as "a way to achieve desirable results at a minimum price” (Zinchenko, and Munipov, 1992). They include both actual and postponed indexes of work outcomes, errors and other manifestations of impaired performance, as well as indicators of mental and physical health. The list of potentially important measures of work efficiency is continually growing up - but it does not mean that the whole range of these measures is to be used in a single empirical study. Only the most crucial characteristics that have influenced the work in each specific situation can be distuinguished by the results of job analysis. As a rule, in the majority of cases only several measures of job performance are selected and considered parallel with indicators of workers' well-being and health. The links between them show how far the achieved results correspond to realization of pragmatic goals and how costly they are at the level of individual expenses.

Secondly, the need of a multidimensional assessment of HFS is stressed that is represented in the idea of structural patterning of HFS syndromes (cf. (Broadbent, 1984; Hockey, and Hamilton, 1983; Leonova, 1998)). These patterns cannot be presented only by simple collection of various manifestations of workers' states. The set of different HFS measures has to be coordinated and structuralized in order to reconstruct changes in the functional structure of work activity as a result of adaptation to various job demands (Leonova, 2005). The functional structure of work activity can comprise the following components (Leonova, 1994; Leonova, et al., 2001a; Zinchenko, and Munipov, 1992): 
(a) energetic components of activity execution, measured by physiological and psychophysiological indicators;

(b) operational components of mental activity, represented by indicators of cognitive functioning;

(c) reflexive components, included evaluations of dominant motives and drives, subjective feelings, and affective reactions;

(d) resulting characteristics of job performance and overt behavior.

The above mentioned components of the work activity's functional structure directly correspond to the main group of methods traditionally used for the diagnostics of workers' states: physiological, cognitive, subjective and behavioral tests (Gaillard, and Wientjes, 1994; Gopher, and Kimchi, 1989; Leonova, 1994; Simonson, and Weiser, 1976). To provide an evaluation of HFS in each particular study, it is important to select those methods which are most relevant to the specifics of job content, dominant workloads and stressors, personnel' work attitudes, etc.

Another important goal consists in finding the way for integration of these heterogeneous data (Hockey, and Hamilton, 1983; Leonova, 1998; Simonson, and Weiser, 1976). A solution to this problem cannot be reduced only to seeking adequate formal procedures for data compression. This thesis is set against clumsy attempts to create some "universal score" or "absolute formula" of fatigue or stress, where a researcher resembles a naive schoolboy "... who mentally adds kilograms and kilometers in a single sum" (Vygotsky, 1983, p. 273). A comprehensive integrative solution needs a thorough interpretation of HFS that specifies involved compensatory mechanisms, reveals the ways in which adaptive resources and coping strategies are utilized, or - in more general terms depicts the activity regulation processes (Hockey, and Hamilton, 1983; Leonova, 1998; Leonova, et al., 2001b).

The most general methodology for analysis of functional organization of human activity was proposed by A.N. Leontiev (Leontiev, 1981). According to the main postulates of his Activity Theory, all psychological functions or mental processes can be regarded as a specific form of internal activity. Central to this theory is the idea about a structural identity of external (behavioral) and internal (mental) planes of activity. Used in practice, this idea helps to overcome a barrier in the description of objective job demands and responses of an acting person. It is also proposed in this theory that any kind of human activity, including work activity, should be described in terms of three hierarchical levels:
- as activity in the whole: representing coordination of objective purposes of activity and actual motives (or drives) of an acting person;

- as a set of distinct actions: outlining relations between particular objective tasks and subjectively accepted task-oriented goals;

- as a set of operations: specifying how an action is executed in particular circumstances (resource-dependent operations).

This descriptive scheme is useful for analysis of activity regulation processes in two dimensions: (1) a vertical dimension that represents relationships in/between hierarchical levels "activity - action - operation", and (2) a horizontal dimension where a correspondence of "job/ professional demands - responses of a working person" is outlined (Leonova, et al., 2001b; Zinchenko, and Munipov, 1992). For instance, changes in dominant workers' drives and subjectively accepted goals can be precisely defined by discovering relationships between the levels "activity - actions". It should be mentioned that these motivational shifts are one of the most important regulatory factors in dynamics of human states (Cox, and Ferguson, 1994; Eysenck, 1982; Hackman, and Oldham, 1980). The analysis of plastic transformations between the levels "action -operations" helps to identify changes in the microstructure of an on-going activity flow (Gopher, and Kimchi, 1989; Velichkovsky, 1988; Zinchenko, Leonova, and Strelkov, 1985). Implementation of these basic ideas in empirical research stimulated the development of the activity regulation approach to HFS (Leonova, et al., 2001a). In many respects this approach is close to the state-regulation paradigm that is well-established in contemporary Western stress research (Gaillard, and Wientjes, 1994; Hockey, 1993; Leonova, et al., 2001b).

\section{Structural analysis of HFS}

One of the most important issues for the activity regulation approach to HFS is the development of structural methods for HFS assessment. The analysis of changes in microstructure of cognitive and sensory-motor processes has been successfully used for this purpose (Baddely, 1986; Leonova, 1994; Simonson, and Weiser, 1976). In different experimental studies it has been shown that specific job demands and stressors can selectively affect different stages of human information processing (Baddely, 1986; Broadbent, 1984; Eysenck, 1982; Leonova, 1998). For instance, the effects of fatigue on symbolic information processing in 
short-term memory (according to the multistore memory model (Atkinson, Shiffrin, 1971)) seem to be mainly related to distortions in control operations such as rehearsal, simple serialization and processing in working memory (Leonova, et al., 2001b). Other types of stressors have distinct effects on the same processing system. For example, monotony affects the operations of masking and coding of information in sensory memory, and also distorts preparations of a motor response. Negative emotional strain impairs retrieval operations and organization of motor responses. A battery of cognitive tests was elaborated for a differentiation of such patterns of microstructural changes, which was validated in a series of empirical studies on operators of tele-communicational systems, microscopists, and air-traffic controllers and pilots (Leonova, 1994; 1998; Zinchenko, and Munipov, 1992).

A good illustration of the microstructural changes in terms of breakdown in control operations and increased required mental efforts is given by the famous S. Sternberg memory search task (Sternberg, 1975). It is well known that this task is usually solved by using a sequential exhaustive short-term memory search which is the fastest and most "economic" short-term memory search strategies. Nevertheless, empirical data suggest that different stressors can challenge the priority of this strategy (Leonova, 1998). For instance, in one of our studies the state of fatigue induced by an 8-hour working shift in desktop operators led to a change of the dominant search strategy; which became the exhaustive self-terminating search. This startegy is more "costly" because it requires the utilization of addition conscious resources (Sternberg, 1975). Negative emotional strain experienced by students during exams (i.e., "examination stress") produced deterioration in search strategies which lost their regular character. On the other hand, positive emotional mobilization in the same situation strengthened the optimal search strategy and even stimulated a shift to a more efficient, parallel processing mode (cf. the model of R.C. Atkinson and J. Juola (Velichkovsky, 1988)). The summarized data of described effects are presented in Table 1.

These examples of using microstructural cognitive methods show that they give more comprehensive diagnostic information in comparison with traditional performance tests. With the help of the last ones only indicators of total productivity and speed of task execution are obtained. these indicators are not suitable for a detailed analysis of impairments in cognitive functioning. The microstructural tests enrich psychological in-
Effects of HFS dynamics on memory search strategies in S. Sternberg recognition task

$(R T(+)$ - reaction time of positive responses; $R T(-)$ - reaction time of negative responses; $n$ - the size of memory set)

\begin{tabular}{lll}
\hline \multirow{2}{*}{ HFS syndromes } & \multicolumn{2}{l}{ Linear equations of reaction time / Memory search strategy } \\
\cline { 2 - 3 } & Before the load & After the load \\
\hline $\begin{array}{l}\text { Fatigue at the end of } \\
\text { an 8-hours work shift } \\
\text { (desktop operators, }\end{array}$ & $\mathrm{RT}(+)=417+93 \mathrm{n}(-)=484+101 \mathrm{n}$ & $\mathrm{RT}(+)=498+48 \mathrm{n}$ \\
26 subjects) & \multicolumn{1}{c}{$\rightarrow$} & $\mathrm{RT}(-)=527+99 \mathrm{n}$ \\
Exhaustive successive search & $\begin{array}{l}\text { Self-terminating } \\
\text { successive search }\end{array}$ \\
\hline $\begin{array}{l}\text { Mental mobilization } \\
\text { during 30 min execu- } \\
\text { tion of simple arithme- }\end{array}$ & $\mathrm{RT}(+)=348+55 \mathrm{n}(-)=398+57 \mathrm{n}$ & $\mathrm{RT}(+)=478+6.4 \mathrm{n}$ \\
tic tasks (18 subjects) & $\mathrm{Exhaustive} \mathrm{successive} \mathrm{search}$ & $\mathrm{RT}(-)=456+58 \mathrm{n}$ \\
\hline $\begin{array}{l}\text { Destructive form } \\
\text { of examination stress } \\
\text { (17 subjects) }\end{array}$ & $\mathrm{RT}(+)=463+38 \mathrm{n}$ & Trend to parallel \\
& $\mathrm{RT}(-)=509+59 \mathrm{n}$ & $\mathrm{RT}(+)=427+37 \mathrm{n}$ \\
& $\mathrm{Mixed}$ search strategy & $\begin{array}{l}\mathrm{RT}(-)=501+78 \mathrm{n} \\
\text { Self-terminating }\end{array}$ \\
\hline $\begin{array}{l}\text { Productive form } \\
\text { of examination stress } \\
\text { (19 subjects) }\end{array}$ & $\mathrm{RT}(+)=451+39 \mathrm{n}$ & successive search \\
\hline
\end{tabular}

terpretation of HFS by a specification of internal tools (mental skills and operations, cognitive strategies, etc.) that are applied in order to cope with actual job demands. The efficiency of the use of such internal tools can be evaluated in terms of more or less "costly" processing modes (e.g. expenses of conscious resources), transformations in strategic goals, etc. (Baddely, 1986; Broadbent, 1984; Hockey, 1993; Velichkovsky, 1988). Also, "weak points" in the processing systems can be localized by indication of those cognitive operations that are distorted under the influence of specific workloads and stress factors (Hockey, 1993; Leonova, 1998).

The same tendency is observed in the development of other types of structural diagnostic methods: behavioral measures (e.g., a microstructure of motor actions, verbal behavior; for review see (Leonova, 1994)) and subjective tests (structural checklists, complex subjective scales and questionnaires (Cox, and Ferguson, 1994; Leonova, et al., 2001a; Zinchenko, Leonova, and Strelkov, 1985)). The use of these meth- 
ods provides additional sensitive indicators for multilevel HFS assessment. For instance, the most elaborated subjective tests have a complex structure that reflects certain aspects of subjective attitudes and feelings. Despite some contextual differences, it is possible to identify some common groups in the structure of these tests: (a) symptoms of actual wellbeing and subjective comfort/discomfort; (b) dominant affective tone; (c) main motivational trends; and (d) personal attitudes to current situation. These groups of symptoms are concerned with two principal types of reflexive acts which ensure activity regulation at the most general leve The first one refers to the reflection of the state of affairs in a current situation (in the dimension "motives - subjectively accepted goals"), the second one - to the reflection of the results of actions and programming prospective behavior (in the dimension "subjective accepted goals - results") (Kuhl, 1983). The patterning of such multiple subjective feelings in coordination with the principal types of reflexive acts helps to clarify changes in actual motives and subjective appraisals of the situation. It has critical value for understanding the dynamics of HFS.

\section{Integrative evaluation of HFS syndromes}

Despite the development of sophisticated diagnostic methods, the problem of integrative evaluation of HFS syndromes is not yet completely solved. The decades of searching for simple measures or a "universal formula" for a straightforward identification of HFS show the futility of such attempts (Hockey, and Hamilton, 1983; Sternberg, 1975; Vygotsky, 1983). It seems that a more constructive way to solve this problem relates to the classification of the typical diagnostic tasks which are most important from a practical viewpoint (Sternberg, 1975). In general, three classes of such tasks can be set apart (Gopher, and Kimchi, 1989; Hockey, and Hamilton, 1983; Zinchenko, and Munipov, 1992) corresponding to the following empirical questions:

- Are workers' states similar or different (e.g. compared to some "optimal" or "normative" state)?

- Are the workers' states changing over time (e.g. are there changes in workability or in accumulation of acute stress reactions)?

- What is the specific form of the state experienced by the worker (e.g. how can we define the HFS syndromes in terms of specific types of fatigue, emotional mobilization, stress, etc.)?
All these tasks are grounded in multilevel HFS assessment, but the types of requested diagnostic solutions are rather different. Therefore, the procedures of statistical analysis and interpretation of "raw" sets of HFS data have to be differentiated:

(a) in the first case, it is necessary only to compare two or more HFS patterns without their deep qualitative characteristics;

(b) in the second case, the main tendency in changes on a time-scale should be determined;

(c) in the third case, an in-depth description of the HFS syndrome is to be given by explaining the relationships between different symptoms.

The types of diagnostic solutions for each of these tasks refer to socalled "strategies of data integration" (Leonova, 1994; 1998). The main characteristics of these strategies are presented in Table 2.

Table 2

Strategies of HFS data integration in different diagnostic tasks

\begin{tabular}{|c|c|c|c|}
\hline $\begin{array}{c}\text { Types of empirical } \\
\text { questions }\end{array}$ & $\begin{array}{l}\text { Diagnostic } \\
\text { solution }\end{array}$ & $\begin{array}{c}\text { Basic } \\
\text { operations }\end{array}$ & $\begin{array}{c}\text { Formal } \\
\text { procedures }\end{array}$ \\
\hline $\begin{array}{l}\text { I. Are the states si- } \\
\text { milar or different? } \\
\text { (HFS rough qualifi- } \\
\text { cation) }\end{array}$ & $\begin{array}{l}\text { Distinction and labeling } \\
\text { of HFS in terms of simple } \\
\text { dichotomies, e.g. "positi- } \\
\text { ve - negative", "optimal-de- } \\
\text { ficient", etc. }\end{array}$ & $\begin{array}{l}\text { Comparison } \\
\text { and binary } \\
\text { classification }\end{array}$ & $\begin{array}{l}\text { - Pattern recogni- } \\
\text { tion algorithms } \\
\text { - Frequency ana- } \\
\text { lysis ( } \chi 2 \text {, etc.) } \\
\text { - Expert's eva- } \\
\text { luations }\end{array}$ \\
\hline $\begin{array}{l}\text { II. Is there states } \\
\text { dynamics? } \\
\text { (Changes in HFS } \\
\text { on time-scale) }\end{array}$ & $\begin{array}{l}\text { Evaluation of trends and } \\
\text { demarcation of main sta- } \\
\text { ges in dynamics of HFS at } \\
\text { certain periods of time, e.g. } \\
\text { stages in dynamics of fa- } \\
\text { tigue during work, critical } \\
\text { stages in the development } \\
\text { of stress reactions, etc. }\end{array}$ & $\begin{array}{l}\text { Order- } \\
\text { ing and } \\
\text { detection } \\
\text { of changes }\end{array}$ & $\begin{array}{l}\text { - Analysis of vari- } \\
\text { ance } \\
\text { - Regression } \\
\text { analysis } \\
\text { - Non-parametric } \\
\text { tests }\end{array}$ \\
\hline $\begin{array}{l}\text { III. What is the } \\
\text { state? } \\
\text { (Qualitative specifi- } \\
\text { cation of HFS) }\end{array}$ & $\begin{array}{l}\text { Structural description of } \\
\text { HFS syndromes in terms } \\
\text { of specific forms of states, } \\
\text { e.g. depicting the types } \\
\text { of fatigue, stress, mental } \\
\text { strain, etc. }\end{array}$ & $\begin{array}{l}\text { Patterning } \\
\text { and struc- } \\
\text { turalization }\end{array}$ & $\begin{array}{l}\text { - Correlation } \\
\text { analysis } \\
\text { - Factor analysis } \\
\text { - Cluster analysis } \\
\text { - Multidimensional } \\
\text { scaling }\end{array}$ \\
\hline
\end{tabular}


The above mentioned strategies of data integration do not exclude each other. They can be implemented dependent on different practical needs or required ways of job optimization. A successive application of these strategies gives an opportunity to indicate (1) substantial deviationsof HFS from an optimal/normative level (i.e. to show the necessity to improve the situation); (2) critical time interval(s) when the risky trends appears in the HFS dynamics; (3) specific HFS syndromes that can be analyzed in terms of activated regulatory mechanisms. The realization of these strategies will be illustrated by the results of two empirical studies.

\section{Example 1: HFS dynamics during}

\section{fire-fighting shifts in Chernobyl Zone}

The occupational group of fire-fighters plays the most important role in emergencies. The risks of this job are very high even in the case of ordinary fires, and they increase greatly in more extreme situations. During their work fire-fighters "have no right" to be careless or make a mistake: any false action can lead to serious damage of human health and deaths, as well as to further complication of the critical situation. So the factors which might influence human reliability are of great significance for the efficient and safe work in this profession.

The reliable work of fire-fighters does not depend only on professional training and physical endurance. Many psychobiological and social factors influence their job (for review see (Maryin, et al., 1992)). The problem of disturbances of fire-fighters' health and well-being is one of the most important among them. This objectively manifests in a high sick rate and a wide spectrum of health disorders among these professionals (Alexandrovsky, et al., 1991). Also, different forms of behavior and social dysadaptation as well as many clinical forms of mental health deterioration are often cited as the greatest danger to the reliability of fire-fighters' work (Leonova, et al., 2001b; Maryin, et al., 1992).

In the present study an attempt was made to identify the main risk factors for well-being and health in a group of fire-fighters, who dealt with the consequences of the Chernobyl Accident. The fire-fighters worked systematically in the Chernobyl Zone for several years after the accident in order to keep the situation under control, including recurrent extinctions of local explosions and fires. The initial set of data was collected directly in the Chernobyl Zone under guidance by professor
M.I. Maryin (Psychological Department of All-Russian Research Institute for Fire Fighting) and later it was processed by us in the Laboratory of Work Psychology, Moscow State University (Leonova, et al., 2001b).

A part of this empirical study deals with evaluations of HFS dynamics during regular working shifts in the Chernobyl Zone in 1992-1993, more than five years after the Accident. By this time the work of firefighters' teams became relatively "routine": inspection of the territory of the Station, detection of flare-ups and pollutions, and elimination of the hazardous events. Still, the danger of radioactive contamination, as well as the effects of other job-related stressors remained at a relatively high level.

As the data of a prior job survey suggest, the heightened level of job demands, both physical and psychological, is adequately reflected by the personnel. Also, the majority of fire-fighters named their dominant job motivation as "to work at any price" (Leonova, 1998; Leonova, et al., 2001b). In this case, the direct and most common way to cope with difficulties consists in extreme mobilization of psychophysiological resources that helps to maintain performance at a fairly high level (cf. (Alexandrovsky, et al., 1991; Gaillard, and Wientjes, 1994; Hockey, 1993). The answer to the question - "How close are the effects of such mobilization to the limits of human capacities?" - was one of the main purposes of our study.

A group of 25 fire-fighters participated in HFS assessment sessions. All subjects were tested twice - (1) at the beginning and (2) at the end of a 12-hours working shift. A set of diagnostic methods includes standard physiological measures, subjective tests for evaluation of actual well-being and emotions, and performance characteristics (see Table 3). The significance of changes between two diagnostic cuts was evaluated by the Student $t$-criteria, separately for each single indicator. Then, to characterize the HFS syndromes at the beginning and at the end of the shift, the factorization of the data was done by the method of principal components.

A negative HFS dynamics from the beginning to the end of the working shift is clear manifested for the majority of indicators (see Table 3). Significant changes in physiological indicators show the increasing symptoms of intensive energetic overstrain and imbalance in the vegetative regulation system at the end of the shift. Negative tendencies in the subjective sphere are represented by a pronounced decrease of subjective comfort and reduction in productive moods. Also, grow- 
ing feelings of anxiety and depression was observed at the end of the shift. Changes in performance manifested itself in decreased speed of performance as shown by longer reaction time in a sensory-motor test. According to these data the functional status of fire-fighters at the end of working shift is seriously impaired, especially with respect to extremely high exhaustion of physiological and mental/emotional resources. Therefore, a pessimistic prognosis of reliability of job performance can be done - continuation of work or lack of full rehabilitation may lead to the collapse of activity.

Table 3

Dynamics of single HFS indicators during the fire-fighter's working shifts

(by Student t-criteria, $n=25$, significance levels: ${ }^{*} p<.05$; ${ }^{* *} p<.01$;

$$
[-] \text { - negative trends) }
$$

\begin{tabular}{|c|c|c|c|c|c|}
\hline \multirow[t]{2}{*}{ Measures } & \multirow[t]{2}{*}{ Indicators } & \multicolumn{2}{|c|}{$\begin{array}{c}\text { Time of the shift } \\
\text { (means) }\end{array}$} & \multirow[t]{2}{*}{ t-value } & \multirow[t]{2}{*}{ Interpretation } \\
\hline & & Beginning & End & & \\
\hline \multicolumn{6}{|c|}{ Physiological indicators } \\
\hline Heart Rate & Pulse (beats / min) & 68.5 & 87.0 & $5.5^{\star *}$ & {$[-]$ Increase } \\
\hline \multirow[t]{2}{*}{ Blood Pressure } & Systolic $(\mathrm{mm} \mathrm{Hg})$ & 120.2 & 122.0 & .54 & no changes \\
\hline & Diastolic $(\mathrm{mm} \mathrm{Hg})$ & 75.8 & 83.9 & $3.81^{\star *}$ & [-] Increase \\
\hline \multirow[t]{3}{*}{ EKG } & $\begin{array}{l}\text { P- interval } \\
\text { amplitude }(m V)\end{array}$ & 2.1 & 1.8 & $2.20^{*}$ & [-] Decrease \\
\hline & $\begin{array}{l}\text { T- interval } \\
\text { amplitude }(m V)\end{array}$ & 4.9 & 5.7 & $3.83^{* *}$ & [-] Increase \\
\hline & $\begin{array}{l}\text { Vago-symphathetic } \\
\text { coefficient }\end{array}$ & 42.8 & 31.6 & $3.99^{* *}$ & [-] Decrease \\
\hline EDR & $\begin{array}{l}\text { Skin resistance } \\
(\mathrm{K} / \mathrm{Ohm})\end{array}$ & 3.2 & 4.4 & $2.31^{*}$ & [-] Increase \\
\hline \multicolumn{6}{|c|}{ Subjective indicators } \\
\hline \multirow[t]{3}{*}{ Well-being scale } & Subjective comfort & 5.6 & 4.1 & $3.72^{\star \star}$ & [-] Decrease \\
\hline & Activity & 4.8 & 4.1 & $2.40^{*}$ & [-] Decrease \\
\hline & Mood & 4.8 & 4.4 & $2.53^{*}$ & [-] Decrease \\
\hline Lusher test & Anxiety/Depression & 14.6 & 18.5 & $2.54^{*}$ & {$[-]$ Increase } \\
\hline \multicolumn{6}{|c|}{ Performance characteristics } \\
\hline Dynamometry & Muscular strength $(\mathrm{kg})$ & 52.9 & 53.8 & .27 & no changes \\
\hline $\begin{array}{l}\text { Simple sensory- } \\
\text { motor reaction }\end{array}$ & Reaction time (ms) & 315 & 361 & 2.33 & {$[-]$ Increase } \\
\hline
\end{tabular}

A qualitative interpretation of HFS syndromes at the beginning and at the end of the shift were done with the help of factor analysis. Although in both cases the obtained factor solutions consisted of three main factors, their component structures are quite different. Accordingly, two different HFS syndromes can be recognized:

- In the beginning of the shift, the factor solution corresponds to the state of high alertness with the well-distinguished components of emotional mobility and performance activation (factor $1 ; 24,4 \%$ of variance); high subjective involvement in job (factor 2; 16, 2\% of variance); intense energetic mobilization (factor $3 ; 12,7 \%$ of variance).

- In the end of shift, the content of the factor solution is rather different and can be interpreted as a state of deep physical and mental exhaustion that includes the components of subjective exhaustion and fatigue (factor 1; 19,3\% of variance); physiological exhaustion and imbalance (factor 2; 16, 1\% of variance); dominance of inhibitory processes and emotional tension (factor $3 ; 14,2 \%$ of variance).

Radical HFS changes from high level of alertness to deep exhaustion during one working shift were an everyday experience of the firefighters at the Chernobyl Zone. Both the acute negative effects and their accumulation over long periods of work are genuinely dangerous for work efficiency and especially for health of these workers (Alexandrovsky, et al., 1991; Leonova, et al., 2001b). It is important to mention that such negative results cannot be explained only by extremely high objective demands that exceed human capacities to cope with them. The tested fire-fighters' teams worked in relatively "routine" work situations and were well-protected. The results of furthers investigations show that the intensity of acute stress responses and HFS deterioration have been stimulated by (1) dissociated subjective appraisal of the situation (an irradiation of anxiety and fears, like feelings "this evil radiation is everywhere") and, as a consequence, (2) co-existence of conflicting motives (high job involvement vs. avoidance of vital dangers). The impossibility to solve these principal conflicts in the given work situation had led to using inappropriate or too costly individual strategies of activity regulations, e.g. non-stop emotional tension and physiological extra-mobilization. Accordingly, a specialized set of stress management techniques has been developed for improving the HFS dynamics in this professional group (Leonova, et al., 2001a; Maryin, et al., 1992). 


\section{Example 2: Effects of interruptions \\ on computerized office work}

Another example of implementation of integrative strategies for HFS evaluation concerns a principally different type of work - the execution of typical computerized tasks in office environment under the influence of interruptions. Although interruptions are daily occurring events for most working people, few studies have been done on the evaluation of their impact on work efficiency (see, for example, (Gillie, and Broadbent, 1984)). In our research, the effects of interruptions on computerized task performance and underlying regulatory processes were examined (Zijlstra, Roe, and Leonova, 1999). Two parallel experimental studies were carried out in the Netherlands and in Russia, using a common conceptual framework and overlapping design. Below we will consider only the results of the Russian experiments.

In our study employees with relevant work experience executed realistic text editing tasks in a simulated office environment, while the appearance and complexity of interruptions were experimentally manipulated. "Interruptions" were defined as events which resulted in the cessation and postponement of on-going activity. Typical for interruption is that the main activity is resumed after a time interval. Accordingly, it was hypothesized that interruptions (1) would cause deterioration of performance; (2) evoke strategies to compensation of this deterioration; (3) affect subjects' well-being and emotions; and (4) raise the level of mental efforts and activation. It was also supposed that greater complexity of interruptions could enhance the expected effects. In order to check these hypotheses the experimental study was organized as follows.

Participants of the experiments worked in the simulated office twice, each time for about half of a day. Each research day consisted of two experimental sessions - "without" and "with" interruptions (the independent variable "presence of interruptions" which varied on two levels: zero and two interruptions per session). The interruptions in a single experimental session were either "simple" or "complex" (the independent variable "complexity of interruptions"). Both mentioned independent variables were tested in within-participant analysis of variance.

During the experimental sessions participants worked on standardized text editing task of moderate complexity that included various operations, like replacing text fragments, making hand-written correc- tions, adjusting layout, etc. That was the main task which had to be performed on a text file using a word processing program. The execution of this task could be interrupted by a telephone call from the experimenter with the request to perform an additional (interrupting) task. There were no time limits for task execution, and participants were free to choose their own work pace and working method.

The interrupting tasks were created accordingly to two different levels of complexity. The "simple" interruption consisted of a request for some irrelevant information, e.g. to look a telephone number in a notebook, or the year of publication of a particular article. The "complex" interruption consisted of a more elaborate task with a greater similarity to the main task, such as an additional short editing task which required the participants to leave the current document (cf. (Gillie, and Broadbent, 1984)).

Following all experimental sessions, the participants were closely watched and video-recorded from the control room, and a time code was added to the video in order to enable subsequent analysis of performance indicators. In addition, diagnostic "cuts" were conducted immediately before and after the execution of the text editing task. They included testing by a set of psychophysiological, cognitive and subjective measures that could not be taken on-line.

All participants had a short training on performing the tasks and diagnostic tests before the beginning of experiments. At that time they had also to fill in several standardized questionnaires for the assessment of indexes of chronic states and personality traits, used as intermediate variables. The set of diagnostic methods was composed accordingly to the principles of HFS analysis. It consisted of evaluation of following characteristics:

(1) indicators of quality of performance evaluated by number of errors (total number of errors, number of omissions and mistakes) and temporal characteristics of acting (total work time, time of performance main tasks, time of handling with interruptions, etc.);

(2) degree of psychophysiological activation and mental efforts evaluated by Critical Flicker Frequency test (CFF) and Mental Effort Scale (RSME, (Zijlstra, Roe, and Leonova, 1999));

(3) subjective feelings of emotional strain and subjective discomfort evaluated by C.D. Spielberger "State-anxiety scale" and "Actual well-being scale" (Leonova, 1994); 
(4) efficiency of cognitive functioning evaluated by microstructural tests "Working memory" (Baddely, 1986) and "Spatial attention span" (Shiffrin, and Schneider, 1977) (indexes of accuracy, speed and strategy of processing).

In addition, the specialized checklists: "Degree of chronic fatigue" (Leonova, 1994), C.D. Spielberger "Trait-anxiety scale" and "Strelau temperament survey" (STS, indexes of excitation, inhibition, mobility, (Strelau, 1983)) - were used for the evaluation of intermediate effects of chronic states and temperament traits on task performance.

In the Russian study 31 subjects participated in experiments ( $11 \mathrm{fe}-$ male and 20 male, age 17-38 years). All participants had secretarial and administrative tasks besides their professional and managerial duties, and all were experienced users of word processors. Each subject fulfilled the whole experimental program. The effects of independent variables "presence of interruptions" and "complexity of interruptions" - have been analyzed by comparing the indicators in the relevant experimental conditions. Analysis of variance (one-way ANOVA model) and analysis of intercorrelation links in the patterns of diagnostic indicators (by the Pearsons' correlation coefficients and multiple regression analysis) were used for depicting the types of interruption effects.

The results of the comparison of different experimental conditions are presented in Table 4 . As it is shown, the interruptions significantly affect different aspects of the main task execution and HFS manifestations, but their effects are not only disturbing. The presence of interruptions leads to a light decrease in the quality of performance in general and enlargement of total work time. In the same time, the number of the "attentive errors" or omissions decreases in the condition "complex" interruptions. The level of psychophysiological activation (CFF) remains on the same level in the conditions "without" and "with" interruptions, but it is significantly higher in the condition "complex" interruptions. The degree of mental efforts does not change under the influence of presence of interruptions although a tendency to increasing RSME appears in the condition "complex" interruptions. Also a tendency to increasing emotional strain was found in the condition "with" interruptions, which became stronger in the condition "complex interruptions". Indicators of cognitive functioning show rather divergent dynamics under the influence of interruptions. In the condition "with interruption" the speed of information processing rises in both cognitive tests; and the strategy of

Effects of interruptions: summary data for comparison of two experimental conditions

(by results of one-way ANOVA, $n=31, d f=1 / 31$; $[+]$ - positive trends; [-] - negative trends)

\begin{tabular}{|c|c|c|}
\hline Indicators & $\begin{array}{l}\text { Comparison } 1 . \\
\text { "Without" vs. "With" } \\
\text { Interruptions }\end{array}$ & $\begin{array}{c}\text { Comparison } 2 . \\
\text { "Simple" vs. "Complex" } \\
\text { Interruptions }\end{array}$ \\
\hline \multicolumn{3}{|c|}{ Performance } \\
\hline Number of Errors & $\begin{array}{l}{[-] \text { Total number of errors - }} \\
\text { increase }(\mathrm{F}=3.87, \mathrm{p}<.05)\end{array}$ & $\begin{array}{l}{[+] \text { Number of omissions - }} \\
\text { decrease }(\mathrm{F}=4.93, \mathrm{p}<.05)\end{array}$ \\
\hline $\begin{array}{l}\text { Duration of Task } \\
\text { Performance }\end{array}$ & $\begin{array}{l}{[-] \text { Total work time - increase, }} \\
(\mathrm{F}=4.66, \mathrm{p}<.05)\end{array}$ & $\begin{array}{l}{[-] \text { Total work time }-} \\
\text { increase }(\mathrm{F}=5.22, \mathrm{p}<.05)\end{array}$ \\
\hline \multicolumn{3}{|c|}{ Activation and effort } \\
\hline CFF & & $\begin{array}{l}{[-] \text { CFF - increase }(\mathrm{F}=4.78,} \\
\mathrm{p}<.05)\end{array}$ \\
\hline Mental Effort & & $\begin{array}{l}{[-] \text { RSME }- \text { increase }} \\
(\mathrm{F}=3.41, \mathrm{p}<.06)\end{array}$ \\
\hline \multicolumn{3}{|c|}{ Subjective feelings } \\
\hline Actual Well-Being & & $\begin{array}{l}{[-] \text { Subjective comfort }-} \\
\text { decrease }(\mathrm{F}=3.69, \mathrm{p}<.08)\end{array}$ \\
\hline State Anxiety & $\begin{array}{l}{[-] \text { Emotional strain }- \text { increase }} \\
(\mathrm{F}=2.79, \mathrm{p}<0.10)\end{array}$ & $\begin{array}{l}{[-] \text { Emotional strain }-} \\
\text { increase }(\mathrm{F}=5.79, \mathrm{p}<0.05)\end{array}$ \\
\hline \multicolumn{3}{|c|}{ Cognitive functioning } \\
\hline Working Memory & $\begin{array}{l}{[+] \text { Speed of processing - increase }} \\
(\mathrm{F}=5.03, \mathrm{p}<.05)\end{array}$ & $\begin{array}{l}{[-] \text { Accuracy of processing }} \\
\text { decrease }(\mathrm{F}=4.51, \mathrm{p}<.05)\end{array}$ \\
\hline $\begin{array}{l}\text { Attention } \\
\text { Distribution }\end{array}$ & $\begin{array}{l}{[+] \text { Speed of processing }- \text { increase }} \\
(\mathrm{F}=4.28, \mathrm{p}<.05) \\
{[+] \text { Parallel strategy of processing - }} \\
\text { dominance }(\mathrm{F}=5.13, \mathrm{p}<.05)\end{array}$ & $\begin{array}{l}{[+] \text { Parallel strategy of }} \\
\text { processing }- \text { dominance } \\
(\mathrm{F}=5.13, \mathrm{p}<.05)\end{array}$ \\
\hline
\end{tabular}

parallel processing becomes dominant in the attention span test. In the condition "complex" interruptions the accuracy in the working memory test declines while the ability of performing parallel processing continues to strengthen as indicated by the attention span test.

The diversity of interruption effects can be explained by the involvement of different regulatory mechanisms during the process of the main task execution that compensate for the influence of additional situation- 
al demands. An integrative representation of HFS syndromes helps to analyze these compensatory effects. The method of patterning correlation links (Kuhl, 1983; Leonova, et al., 2001b) between the main groups of diagnostic indicators was used for this purpose.

The correlation's patterns are presented in the graphic form for the conditions "without", "simple" and "complex" interruptions (see Figure 1).

\section{A. Condition "Without Interruptions"}

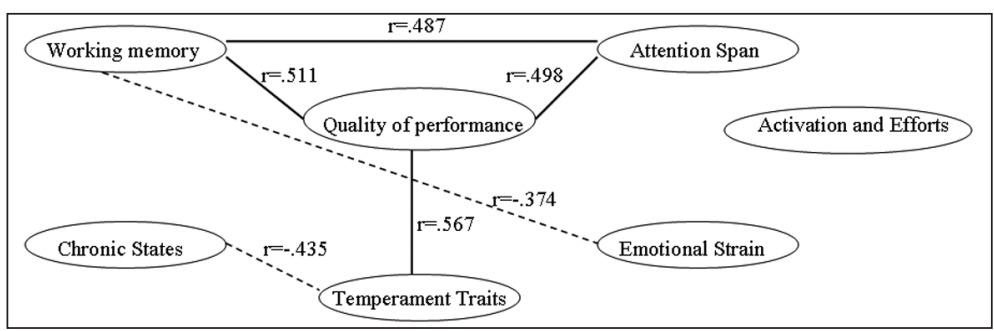

B. Condition "Simple Interruptions"

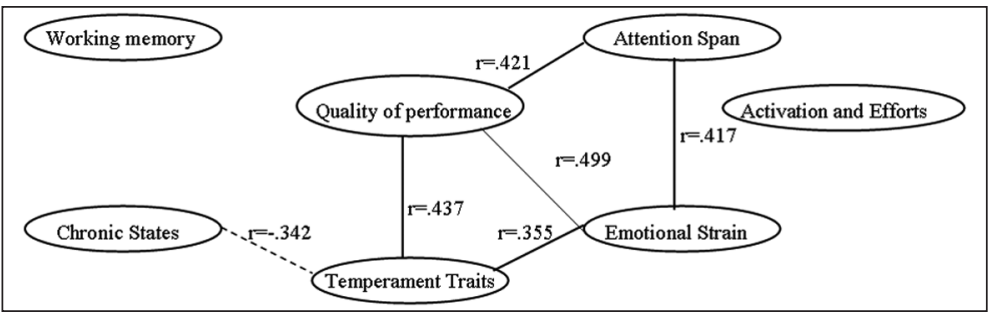

C. Condition "Complex Interruptions"

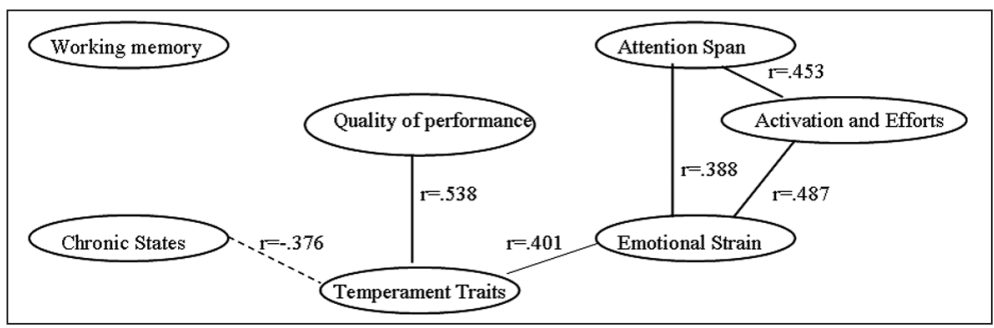

Figure 1. Patterns of significant correlations between main groups of HFS indicators in different interruption conditions
A comparison of the graphs shows that there are substantial differences between them:

A. In the condition "without interruptions" quality of performance is directly linked to indicators of cognitive functioning, i.e. the systems of the successive processing of information in working memory and the parallel strategy of distribution of attention resources (Baddely, 1986; Shiffrin, and Schneider, 1977; Velichkovsky, 1988). These relationships can be eventually modified according to individual characteristics, in our case temperament traits. This pattern of correlations represents the utilization of well-balanced cognitive skills that ensure the execution of familiar tasks in automated mode.

B. In the condition "simple interruptions" the set of significant interrelations changes. Close relationships between quality of performance and indicators of attention distribution and emotional strain are established. The direct links with temperament traits remain strong. However, the balanced relations between two cognitive systems (working memory and attention) are destroyed. The correlation attern shows that automated task execution is deteriorated in this experimental condition (Baddely, 1986; Hockey, 1993). This deterioration is compensated for by a re-distribution of attentional resources and an increase in emotional strain.

C. In the condition "complex interruptions" almost all direct links between quality of performance and other groups of indicators disappeared. The only exception is the strong correlation with temperament traits. These individual characteristics straightly relate to indicators of emotional strain, which are connected with indicators of attention distribution and psychophysiological activation (Eysenck, 1982; Strelau, 1983). This suggests that handling more complex interruptions is supplied by individual modes of coping that require additional emotional, attentional and psychophysiological resources.

Summarizing the data, it has to be mentioned that there were no serious damaging effects of interruptions on task performance. It is not surprising since in our experiments well-experienced persons had to perform rather simple tasks in ordinary circumstances. Heterogeneity of single interruption effects (see Table 4 ) demonstrates the plasticity of regulatory processes that helped the subjects to manage such daily occurred hindrances. The nature of this on-going activity regulation can be charaterized by the results of integrative patterning of HFS. In the case of working without interruptions the tasks are performed automatically 
by utilizing well-developed cognitive skills. The appearance of simple interruptions evokes emotional mobilization and enhances the parallel strategy of attentional resources allocation during task execution. Complex interruptions are managed through individualized coping that requires mobilization of more conscious/attentive and psychophysiological resources by mechanisms of emotional energizing. These regulatory transformations allow to keep the results of task performance on a rather high level. In the same time, the changes in the HFS syndromes demonstrate the negative effects of interruptions that reflect the growing internal costs of activity.

It is also important to emphasize the role of individual characteristics, such as temperament traits and coping styles. They influence task execution in all considered conditions but are exceptionally important in the case of complex interruptions. This means that individual modes of coping and compensatory strategies become the most critical feature in the regulation of human activity after an increase in situational demands.

\section{Conclusions}

With the examples presented here we tried to illustrate how an integrative methodology of studying the changes in regulatory mechanisms of work activity by revealing the dominant patterns in HFS dynamics could be realized in practice. The use of this methodology implies a re-orientation of traditional HFS research to a broader context - it takes into consideration not only the characteristics of on-going performance and cognitive functioning of a working person but also his/her emotional and motivational attitudes to job situation. In general, this approach gives an impetus to create more effective psychological technologies for correction and prevention of negative HFS, as well as stressmanagement programs which are based on the analysis of activity deterioration and disturbances of underlying regulatory mechanisms typical for each negative HFS. Recently, the methodology of integrative HFS assessment was implemented in the development and empirical verification of a complex psychodiagnostic and preventive system named Managerial Stress Survey (MSS, (Leonova, 2005)). Further development of the proposed methodology can be achieved by enriched instrumentation of research with the use of more precise microstructural cognitive, reflexive and objective measures.

\section{References}

Alexandrovsky, Yu.A., et al. (1991). Psikhogeniya $v$ ekstremal 'nykh usloviyakh [Psychogenic disorders in extreme conditions]. Moskva: Medicina.

Atkinson, R.C., Shiffrin, R.M. (1971). The control of short-term memory. Scientific American, 225. P. 82-90.

Baddely, A.D. (1986). Working Memory. Oxford: Oxford University Press.

Broadbent, D.E. (1984). Performance and Its Measurement. British Journal of Clinical Pharmacology, 18. P. 55-95.

Cox, T., and Ferguson, E. (1994). Measurement of the Subjective Work Environment. Work and Stress, 8. P.98-109.

Eysenck, M.W. (1982). Attention and Arousal: Cognition and Performance. Heidelberg; Springer.

Gaillard, A.W.K., and Wientjes, C.J.E. (1994). Mental Load and Work Stress as Two Types of Energy Mobilization. Work and Stress, 8. P. 141-152.

Gillie, T., and Broadbent, D.E. (1984). What Makes Interruptions Disruptive? A study of Length, Similarity and Complexity. Psychological Research, 50. P. 243-250.

Gopher, D., and Kimchi, R. (1989). Engineering Psychology. Annual Review of Psychology, 40. P. 431-455.

Hackman, J.R., and Oldham, R.G. (1980). Work Redesign. Addison-Wesley: Reading MA.

Hockey, G.R.L., and Hamilton, P. (1983). The Cognitive Patterning of Stress States. In G.R.L. Hockey (ed.). Stress and Fatigue in Human Performance. N.Y.: Wiley. P. 331-362.

Hockey, G.R.L. (1993). Cognitive-Energetical Control Mechanisms in the Management of Work Demands and Psychological Health. In A. Baddely and L. Weisnkrantz (eds.). Attention, Selection, Awareness, and Control: A Tribute to Donald Broadbent. Oxford: Claredon Press. P. 328-345.

Karasek, R.A., and Theorell, T. (1990). Healthy Work, Stress, Productivity, and the Reconstruction of Working Life. N.Y.: Basic Books. Verlag.

Kuhl, J. (1983). Motivation, Konflikt und Hadlungsregulation. Berlin: Springer-

Leonova, A.B. (1994). Industrial and Organizational Psychology in Russia: The concept of Human Functional States and Applied Stress Research. In C.L. Cooper, and I.T. Robertson (eds.). International Review of Industrial and Organizational Psychology, 1994, 9. Chichester: Wiley. P. 183-212.

Leonova, A.B. (1998). Basic Issues in Occupational Stress Research. In J.R. Adair, et al. (eds.). Advances in Psychological Science, 1: Social, Personal and Cultural Aspects. Hove: Psychological Press. P. 307-331.

Leonova, A.B., et al. (2001a). Methodology of Work Safety and Human Error Research in Russia. In V. De Keyser and A.B. Leonova (eds.). Error Prevention and WellBeing at Work in Western Europe and Russia. Dordrecht: Kluwer. P. 105-133. 
Leonova, A.B., et al. (2001b). The activity Regulation Approach in Case Studies of Human Reliability. In V. De Keyser and A.B. Leonova (eds.). Error Prevention and Well-Being at Work in Western Europe and Russia. Dordrecht: Kluwer. P. 153-176.

Leonova, A.B. (2005). Towards a Strategic Stress Management at Workplace: Stress in Medical Doctors' Professions. In P. Richter, H.M. Peiro, and W.B. Shaufeli (eds.). Psychological resources in Health Care System. Muenchen: Rainer Hampp Verlag. P. 97109.

Leontiev, A.N. (1981). Activity, Consciousness, Personality. Englewood Cliffs: Prentice Hall.

Maryin, M.I. et al. (1992). Functional States of Personnel of the fire-fighting Service at the Chernobyl Nuclear Plant during the Liquidation of the Consequences of Accident. In M.I. Bobneva (ed.). Chernobyl'skij sled: Mediko-psikhologicheskie posledstviya radiacionnogo vozdejstviya [The Chernobyl Trace: Medical and Psychological Consequences of Accident]. Moskva: Nauka.

Shiffrin, R.M., and Schneider W. (1977). Controlled and Automatic Human Information Process: Perceptual Learning, Automatic Attention, and a General Theory. Psychological Review, 84. P. 127-190.

Simonson, E., and Weiser, P.C. (1976). Psychological Aspects and Physiological Correlates of Work and Fatigue. Springfield: C.Ch. Thomas,.

Sternberg, S. (1975). Memory Scanning: New Findings and Current Controversies. Quarterly Journal of Experimental Psychology, 27. P. 1-32.

Strelau, J. (1983). Temperament - Personality - Activity. L: Academic Press.

Velichkovsky, B.M. (1988). Wissen und Handeln. Weinheim: VCH Verlagsgesellschaft.

Vygotsky, L.S. (1983). Diagnostika razvitiya i pedologicheskaya klinika trudnogo detstva [Developmental Diagnostics in a Pedological Clinic]. In L.S. Vygotsky. Sobranie sochinenij, tom 5 [Collection of Scientific Works, vol. 5]. Moskva: Pedagogika.

Zijlstra, F.R.H., Roe, R.A., and Leonova, A.B. (1999). Temporal Factors in Mental Work: Effects of Interrupted Activities. Journal of Occupational and Organizational Psychology, 2. P. 163-185.

Zinchenko, V.P., Leonova, A.B., and Strelkov, Yu.K. (1985). Psychometric of Fatigue. L.: Taylor \& Francis.

Zinchenko, V.P., and Munipov, V.M. (1992). Osnovy ergonomiki [Foundations of Ergonomics]. Moskva: Izdatel'stvo Moskovskogo universiteta. 